SciDioc

International Journal of Dentistry and Oral Science (IJDOS)

ISSN: 2377-8075

\title{
Tetracycline Combined With PRF Membrane In A Periodontal Compromised Splinted Incisor To Enhances Soft Tissue Support Despite Poor Oral Hygiene: A Case Report With 1 Year Follow-Up
}

Case Report

Siddharth Narayan $^{1 *}$, Sankari Malaiappan ${ }^{2}$

${ }^{1}$ Department of Periodontics, Saveetha Dental College, Saveetha Dental College and Hospitals, Saveetha Institute of Medical and Technical Sciences, 162, Poonamallee High Road, Chennai 600077, Tamil Nadu, India.

${ }^{2}$ Professor, Department of Periodontics, Saveetha Dental College, Saveetha Dental College and Hospitals, Saveetha Institute of Medical and Technical Sciences, 162, Poonamallee High Road, Chennai 600077, Tamil Nadu, India.

\section{Abstract}

We live in a fast-paced world with continuous change and innovation, despite this change Periodontology has always been regarded as one of the few specialities in dentistry where the chief complaint of patient rarely includes severe pain and usually presents as altered function. In Periodontology, the ideal goal however has always been retaining what teeth are naturally present, treating the chief complaint while simultaneously looking at the larger picture to decide long term beneficial treatment plans. Considering periodontology is a multifactorial infection of primary bacterial origin usingsplints alone to address cosmetic and functional needs is not sufficient and there is a need to induce surface decontamination of infected root surface. When combining all three conditions of antibiotic local drug application, along with a biomimetic membrane for soft tissue adhesion and splinting to dissipate biting forcescan retains the patient's natural teeth.

It is also the responsibility of the clinician to asses and select ideal clinical situations where treatment would not be able to regenerate periodontal soft tissue and those which would further aggravate periodontal destruction of adjacent teeth.Keeping all these facts in mind the following case serious revisits root conditioning, splinting and enhanced soft tissue adhesion.

Keywords: Splinting, Mobility; Periodontal Therapy; Retained Mobile Teeth; Management Of Periodontally Compromised Teeth.

\section{Introduction}

Edentulism, defined as the complete loss of all dentition, is a worldwide phenomenon. According to the criteria of the World Periodontology is a combined science dealing with both hard as well as soft tissue which takes an interdisciplinary dental approach to treat chief complaint while simultaneously keeping in mind any other problems which may arise in the future. Considering Periodontitis is an established multifactorial tissue invasive infection of prime bacterial origin, inadvertent repetitive mechanical debridement alone is not sufficient in treatment and requires antimicrobial therapy as well. [1] The most common complaints with which patients are referred to this department is tooth mobility along with bleeding gums and difficulty chewing.
Early animalstudies models have suggested progressive attachment loss around involved teeth eventually resulted in the increased severity of mobility as compared to teeth which were splinted $[2,3]$. Splinting multiple teeth together causes dissipation of forces acting on individual teeth to a group of teeth enabling them to act as a functional unit passively, without actual application of any force on adjacent teeth. They are aimed to temporarily relieve and reduce the load acting on the periodontium of affected teeth which is then disturbed in adjacent teeth.Apart from just patients Splinting also installs some extent of confidence within practitioners to carry on with surgical intervention on patients without the fear of aggravated post surgically mobility or exfoliation during flap surgery.

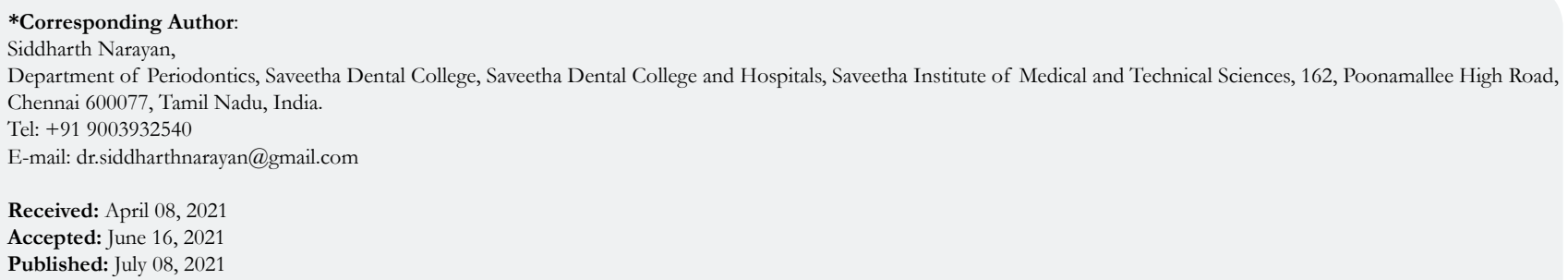

Citation: Siddharth Narayan, Sankari Malaiappan. Tetracycline Combined With PRF Membrane In A Periodontal Compromised Splinted Incisor To Enhances Soft Tissue Support Despite Poor Oral Hygiene: A Case Report With 1 Year Follow-Up. Int J Dentistry Oral Sci. 2021;8(7):3155-3157. doi: http://dx.doi.org/10.19070/2377-8075-21000642

Copyright: Siddharth Narayan ${ }^{\circ}$ 2021. This is an open-access article distributed under the terms of the Creative Commons Attribution License, which permits unrestricted use, distribution and reproduction in any medium, provided the original author and source are credited. 
The following case reports are a few instances when splinting along with antibiotic root conditioning with platelet rich fibrin was found to be a beneficial tool for the clinician as well as the patient.

\section{Case Presentation}

A 38 year old male patient presented with a chief complaint of mobile tooth in the upper right front tooth region for the past 6 months with an occasional history of bleeding gum on brushing for the past 6 months. He was systemically healthy and had no apparent relevant medical history and no deleterious habits. Clinical examination revealed fiery red coloured gingiva, soft and oedematous in consistency with enlargement interdental papilla and swollen marginal gingival in 11,12,13,21,22, 23, 31,32,41,42. Periodontal examinationrevealed a probing depth of around5 mm uniformly on Buccal aspect,with a clinical attachment loss of $9 \mathrm{~mm}$ on disto-buccalaspect of 11 and $8 \mathrm{~mm}$ on mesio-buccal and mid-buccalaspect.There was also minimal width of keratinised tissue in relation to the incisor with grade- 3 mobility,supra-eruption and exudation from gingival sulcus in relation to $11,12,21,22$. (figure 1)

Clinical and radiographic examination of 11 was done which revealed a periapical radiolucency in relation to 11 (absence of alveolar socket) with bilateral vertical bone loss and no periodontal bone support, ruling out initial treatment plan of surgical reimplantation.Cold test was done on the incisor using tetra-fluoroethylene followed by electronic pulp tester was used to check vitality in relation to 11 further confirmed by. A treatment plan was formulated, as per which patient education, scaling, root planning was donefollowed by which a provisional splint and a full thickness flap would be elevated.

\section{Presurgical provisional splint and phase 1}

The tooth was divided into three halves incisal, middle $3 \mathrm{rd}$ and apical, a horizontal groove was then made using a handpiece (diamond abrasives)in relation to 11 alone along the middle third of the tooth while other teeth were spared. No 26-gauge stainless steel ligature wire was braided and placed in the labial aspect of 11-23 along the middle $3 \mathrm{rd}$ of the teeth. The wire was initially stabilised using $3 \mathrm{M}$ flowable composite resin followed by permanent
A2 body shade for reinforced stability using a Woodpecker curing lamp. Full mouth complete scaling and root planning anaesthesia was done in two appointments separated by a week interval.

\section{Surgical phase}

Under adequate local anaesthesia Lidocaine with 1:80,000 units of adrenaline, A full thickness Kirklandflap was raised using No 15 blade by giving an intra-crevicular incision in relation to buccal aspect of 11-23. A P24 periosteal elevator was used to reflect the flap, debridement was done using Gracey`s curettes while cotton gauge was used to control excessive bleeding. After a thorough debridement Tetracycline 500mg capsule was separated and mixed with normal saline to form a slurry which was then applied on the root surface of 11 for 5 minutes and then washed away using a three-way syringe.

PRF procured using Choukroun`s method [4]was compressed between 2 cotton gauges to form a membrane which was soaked in slurry of tetracycline then placed over the buccal aspect of 11 (figure 2) and the flap was then secured using independent sling silk sutures and Coe pack periodontally dressing was then moulded onto the surgical site.

\section{Outcome and follow up}

The patient was periodically recalled for a follow-up 1 week later, where the periodontal dressing was removed along with the silk suture and the patient was followed for1 year with periodic follow-ups every 3 months, where the splint was re-evaluated and adjustments were made whenever necessary without removing the splint. During 1 year evaluation it was observed that initially red oedematous gingiva had completely healed and matured into attached gingiva despite poor oral hygiene maintenance. (figure 3)

\section{Discussion}

The following case series mentions splinting as a method of stabilisation of mobile teeth while simultaneously tries to emphasise the simple fact that no two patients are the same and they all require custom made treatment plans.

Tetracycline is a broad spectrum antibiotic priorly used in root conditioning with an objective of detoxifying the root surface by

Figure 1. Preoperative clinical frontal picture with Gingival inflammation in relation to 13-23 with supra-eruption of 11.

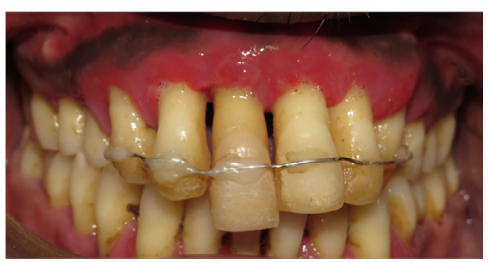

Figure 2. Intraoperative clinical picture of flap surgery with the use of provisional splints, PRF membrane and tetracycline root conditioning.

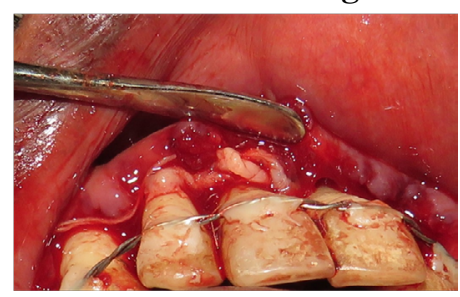


Figure 3. One-year postoperative clinical picture with non-vital 11 back to normal level of Occlusion with evidence of healthy attached gingiva.

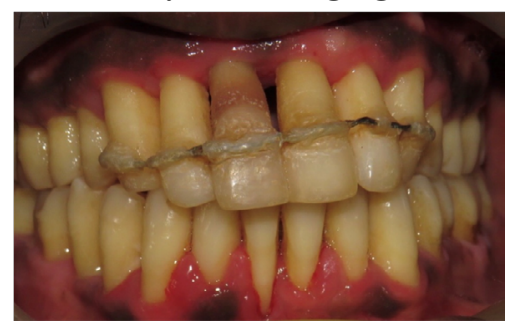

Figure 4. Radiographic evaluation of 11 with preoperative diagnostic RVG and 1 year postoperative RVG: showing no evidence of change in underlying bone.
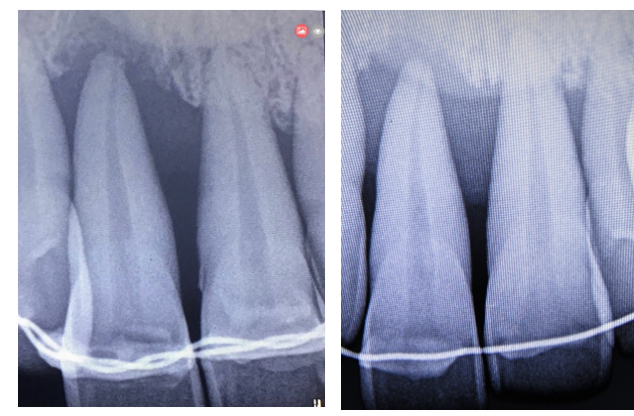

removing smear layer and exposing the collagen matrix that supports migration, proliferation and adhesion of the cells involved in periodontal healing. [5, 6] While comparing removal of smear layer using tetracycline $\mathrm{HCl}$ and EDTA, there was a mean difference of 0.10 and standard error of 0.174 which was found to be insignificant statistically insignificant while there was a significant increase in number of dentinal tubules. [7] In the present case report,systemic tetracycline capsule was used with normal saline as a local drug delivery slurry toprovide a sterile environment for new attachment of gingiva to platelet rich fibrin membrane and tooth surface.

There are three types of Splints a provisional splint, interim splints and permanent splints based on the duration of time. Though initially developed and accepted as a practice to splint mobile teeth especially lower incisors to maintain the patient's natural dentition as long as possible in current day and age clinical practice the most commonly used splints include the provisional or Interim splints. [8] These splints are seen as a measure to prevent not just exfoliation of periodontally compromised teeth but they also assist in appropriate healing of underlying periodontal structure. In periodontology however the use of splints has pushed us more in the direction that a tooth which is not affected by any form of trauma when left on its own can be stabilised in such a manner that it can favour regeneration of the soft tissue component of the periodontium. Studies have proven that bone healing around a tooth structure have been no different with or without the use of splintingbut at the same time they also suggest a psychological action. $[8,9]$ This action can be explained where by not using a splint the doctor is unable to clear or remove Necrotic tissue, granulation tissue or calculus from the site in the fear of Mobilisation or exfoliation of the tooth during the surgical procedure. Periodontal disease which often manifests as mobility of tooth affects patients comfort,aesthetics and function thereby causing psychological changes affecting their quality of life thus it must always be addressed at the earliest to improve psychological health of patients.[10]

The purpose of this case series was to not only emphasise on the importance of retaining natural value of teeth rather than simply replacing all that is lost but it also addresses patient selection. The regenerative potential of platelet concentrates enhanced soft tissue healing around a tooth seen clinically as attached gingiva despite poor overall oral hygiene and no net increase in bone levels.

\section{References}

[1]. Slots J, Rams TE. Antibiotics in periodontal therapy: advantages and disadvantages. J ClinPeriodontol. 1990 Aug;17(7 ( Pt 2)):479-93. PubmedPMID: 2202744

[2]. Kathariya R, Devanoorkar A, Golani R, Shetty N, Vallakatla V, Bhat MY To Splint or Not to Splint: The Current Status of Periodontal Splinting. J IntAcadPeriodontol. 2016 Apr 8;18(2):45-56. Pubmed PMID: 27128157.

[3]. Ericsson I, Giargia M, Lindhe J, Neiderud AM. Progression of periodontal tissue destruction at splinted/non-splinted teeth. An experimental study in the dog. J ClinPeriodontol. 1993 Nov;20(10):693-8. Pubmed PMID: 8276978 .

[4]. Choukroun J, Simonpieri A, Girard MO, Fioretti F, Dohan S, Dohan D. Platelet Rich Fibrin (PRF): un nouveau biomatériau de cicatrisation. Implantodontie. 2004;4(13):229-35.

[5]. Leite FR, Sampaio JE, Zandim DL, Dantas AA, Leite ER, Leite AA. Influence of root-surface conditioning with acid and chelating agents on clot stabilization. Quintessence Int. 2010 Apr;41(4):341-9. PubmedPMID: 20305869.

[6]. Amireddy R, Rangarao S, Lavu V, Madapusi BT. Efficacy of a root conditioning agent on fibrin network formation in periodontal regeneration: A SEM evaluation. J Indian SocPeriodontol. 2011 Jul;15(3):228-34. PubmedPMID: 22028509.

[7]. Nanda T, Jain S, Kapoor D, Kaur H, Nanda S. Comparison of the efficacy of ethylenediaminetetraacetic acid and tetracycline hydrochloride as root conditioning agents: An in vitro study. Journal of the International Clinical Dental Research Organization. 2012 Jan 1;4(1):2.

[8]. Quirynen M, Mongardini C, Lambrechts P, De Geyseleer C, Labella R, Vanherle G, et al. A long-term evaluation of composite-bonded natural/resin teeth as replacement of lower incisors with terminal periodontitis. J Periodontol. 1999 Feb;70(2):205-12. Pubmed PMID: 10102560.

[9]. Andreasen JO, Bakland LK, Andreasen FM. Traumatic intrusion of permanent teeth. Part 3. A clinical study of the effect of treatment variables such as treatment delay, method of repositioning, type of splint, length of splinting and antibiotics on 140 teeth. Dent Traumatol. 2006 Apr;22(2):99-111. Pubmed PMID: 16499633.

[10]. Lopes, Manuela Wanderley Ferreira, Estela Santos Gusmão, Renato de VasconcelosAlves, and RenataCimóes. "Impact of Periodontal disease on quality of Life" RGO.RevistaGaúcha de Odontologia (Online) 59 (June 2011): $39-44$. 